Check for updates

Cite this: RSC Adv., 2017, 7, 36585

Received 15th June 2017

Accepted 17th July 2017

DOI: 10.1039/c7ra06701a

rsc.li/rsc-advances

\title{
Conversion of cellulose rich municipal solid waste blends using ionic liquids: feedstock convertibility and process scale-up
}

\author{
Ling Liang, (iD ${ }^{\text {ab }}$ Chenlin Li, (D) ${ }^{\text {ac }}$ Feng Xu, de Qian He, (D) ab Jipeng Yan, (D) ab \\ Tina Luong, (iD ab Blake A. Simmons, (iD bd Todd R. Pray, (D) ab Seema Singh, (iD de \\ Vicki S. Thompson (D) ${ }^{c}$ and Ning Sun (iD *ab
}

Sixteen cellulose rich municipal solid waste (MSW) blends were developed and screened using an acidassisted ionic liquid (IL) deconstruction process. Corn stover and switchgrass were chosen to represent herbaceous feedstocks; non-recyclable paper (NRP) and grass clippings (GC) collected from households were chosen as MSW candidates given their abundance in municipal waste streams. The most promising MSW blend: corn stover/non-recyclable paper (CS/NRP) at 80/20 ratio was identified in milliliter-scale screening based on the sugar yield, feedstock cost, and availability. A successful scale-up (600-fold) of the IL-acidolysis process on the identified CS/NRP blend has been achieved. The sugar and lignin streams were recovered and characterized. Mass and material energy flows of the optimized process were presented. Feedstock cost for MSW blends was also discussed. Results suggest the promising potential of using MSW as a feedstock blending agent for biorefineries while maintaining sufficient performance and low feedstock cost. The bench scale $(6 \mathrm{~L})$ study is an essential step in demonstrating the scalability of this IL technology.

\section{Introduction}

Human societies generate and accumulate large quantities of municipal solid waste (MSW) that consists of everyday items such as food scraps, waste papers, product packaging, furniture, clothing, yard waste, etc. It is challenging to dispose of MSW given the rising costs of landfilling and environmental concerns. To sustain a healthy environment, there is a need to restrict the indiscriminate discharge of MSW and continue to utilize recyclable materials. For example, the United States Environmental Protection Agency (EPA) has reported that 254 million tons of total MSW were generated in America in 2013 with a $34.3 \%$ recycling rate. ${ }^{1}$ In 2013, paper and paperboard accounted for $27 \%$ of the total MSW. America recovered about 67\% (5.7 million tons) of newspaper/mechanical paper but other paper types like packaging paper, food soiled paper, shredded paper, and waxed or coated paper were not well salvaged. ${ }^{1}$ These products are

\footnotetext{
${ }^{a}$ Advanced Biofuels Process Demonstration Unit, Lawrence Berkeley National Laboratory, Emeryville, CA, USA. E-mail: nsun@lbl.gov; Tel: +1 5104958024

${ }^{b}$ Biological Systems and Engineering Division, Lawrence Berkeley National Laboratory, Berkeley, CA, USA

${ }^{c}$ Energy and Environmental Science and Technology, Idaho National Laboratory, Idaho Falls, ID, USA

${ }^{d}$ Joint BioEnergy Institute, Lawrence Berkeley National Laboratory, Emeryville, CA, USA

${ }^{e}$ Biological and Materials Sciences Center, Sandia National Laboratory, Livermore, CA, USA
}

generally considered non-recyclable paper (NRP) because they are expensive to recycle and are usually landfilled or combusted to generate energy. As such, they can be considered a low value or negative value material due to the tipping fee for landfill. Growth in electricity production from biomass and waste has been observed over the past decade through combustion in many EU countries. ${ }^{2}$ However, the cellulose fraction in these paper materials holds significant potential to be turned into higher value products through bioprocessing. Recovering valuable components from MSW and subsequent reutilization can help reduce waste emissions and also create economic benefits for certain industries.

Renewable biomass has much potential to contribute to current and future energy needs. In a traditional biorefinery scenario, significant attention has been given to agriculturallyderived feedstocks. ${ }^{3,4}$ It has been shown that non-food biomass including agricultural residues (e.g. corn stover, wheat straw, bagasse), energy crops (e.g. switchgrass), and yard wastes (e.g. grass clippings) are important contributors to the more than one billion tons of biomass that could be sustainably available in the United States by 2030.5,6 However the quality and cost of biomass sources can vary widely depending on weather patterns, agronomic practices, harvest methods and geographical locations. ${ }^{7}$ Other associated challenges of focusing on agriculturally-derived feedstocks include carrying capacity of infrastructures to harvest and pre-process feedstocks, developing technologies capable of converting 
feedstocks to consumable energy products cost-competitively, as well as ensuring environmental and public health protection or other benefits. ${ }^{8,9}$ In this regard, MSW shows great potential to serve as a blending reagent to help normalize the composition of biomass input to a biorefinery that has a welldefined tolerance to variations in biomass composition as well as reduce the feedstock cost which contributes significantly to the production costs. ${ }^{\mathbf{1 0}}$

Utilization of different MSW sources for the purpose of decreasing biomass cost while maximizing supply capacity is quickly gaining prominence within the fuel production field. ${ }^{3}$ It has been shown that MSW-derived ethanol use in vehicles reduces net greenhouse gas (GHG) by 58\% compared to gasoline. ${ }^{11}$ Substituting fossil fuels with MSW-derived fuels is a promising strategy to simultaneously meet our energy needs, mitigate greenhouse gas (GHG) emissions, and reduce MSW in landfills. ${ }^{12}$ However, to date the impact of MSW blends has not been extensively studied in terms of sugar conversion efficiency and/or hydrolysate quality.

In order to produce fermentable sugars from feedstocks and improve the downstream processing performance, pretreatment is necessary to reduce the feedstock recalcitrance and increase substrate accessibility. ${ }^{\mathbf{1 3 - 1 6}}$ Different pretreatment methods have been reported such as dilute acid, ${ }^{17-19}$ steam explosion, ${ }^{20}$ irradiation, ${ }^{21}$ dilute alkaline, ${ }^{22}$ hot-water extraction, ${ }^{23}$ soaking in aqueous ammonia, ${ }^{24}$ mechanical size reduction, ${ }^{25}$ ammonia fiber expansion, ${ }^{26}$ ionic liquids (ILs), ${ }^{19,27-29}$ etc. Among various pretreatment technologies, pretreatment using certain ILs enables fractionation and/or solubilization of a wide range of feedstocks due to its unique solvent properties.,.$^{3,19,28,30-35}$ Acid catalyst has been used previously to hydrolyze polysaccharides to monosaccharides following IL pretreatment, which could potentially provide an enzyme-free process with significant reduction of the processing time and material cost. ${ }^{3,32,36}$ It was reported that over $80 \%$ glucose and $90 \%$ xylose were released with the integrated IL-acidolysis process at lab scale. ${ }^{32}$

We have recently reported the IL-acidolysis process focusing on one MSW blend which used office paper waste to simulate MSW blended with corn stover. ${ }^{4}$ The office paper waste used in this recent study were collected from one of the Idaho National Laboratory (INL) buildings and is considered "cleaner" compared to the actual solid waste generated from households. The objective of the current study is to evaluate the sugar conversion and process scalability of different types of MSW blends including non-recyclable paper (NRP) and grass clippings (GC) using the IL-acidolysis technology. The NRP used here was collected from a landfill in Seattle, WA by Cascadia Consulting and closely represents actual household paper waste. The blends were initially screened at lab scale for conversion performance comparison and the most promising blends were selected for scale-up and further process optimization.

\section{Experimental}

\section{Materials}

A $4 \times 4$ matrix of MSW blends was developed using INL's Least Cost Formulation Model. ${ }^{37}$ Blends were developed solely based upon total feedstock cost and did not take quality specifications into account in this study. Corn stover and switchgrass were chosen to represent herbaceous feedstocks. NRP and grass clippings were chosen as MSW candidates given their abundance in municipal waste streams. Blend formulas as well as glucan and xylan contents are listed in Table 1.

Single pass-harvested corn stover was collected in Boone County, Iowa in the autumn of 2011. Alamo switchgrass was harvested in July 2012 from Garvin County, Oklahoma. Both were prepared by staff at INL and were milled to $4 \mathrm{~mm}$ size. Grass clippings were collected in 2014 from various locations in Bonneville County, Idaho, and were dried to less than $10 \%$ moisture and milled to $4 \mathrm{~mm}$. NRP was collected by Cascadia Consulting (Seattle, WA) during a waste composition study conducted in the City of Seattle in July and November, 2014. NRP components consisted of aseptic and polycoated containers and packaging, food soiled paper, shredded paper, waxed or coated paper and cardboard. These materials were dried to less than $10 \%$ moisture and shredded in a crosscut shredder compliant to level 7 National Security Administration guidelines with a $1 \mathrm{~mm} \times 5 \mathrm{~mm}$ shred size. The feedstocks were stored in airtight containers at $4{ }^{\circ} \mathrm{C}$ with room humidity maintained at $64-70 \%$.

Two chloride-based ILs, 1-butyl-3-methylimidazolium chloride $\left(\left[\mathrm{C}_{4} \mathrm{C}_{1} \mathrm{Im}\right] \mathrm{Cl},>99 \%, \quad \mathrm{MW}=174.67\right)$ and 1-ethyl-3methylimidazolium chloride $\left(\left[\mathrm{C}_{2} \mathrm{C}_{1} \mathrm{Im}\right] \mathrm{Cl},>95 \%, \mathrm{MW}=\right.$ 146.62), were purchased from IoLiTec Ionic Liquids Technologies Inc., Tuscaloosa, AL, USA. $\left[\mathrm{C}_{4} \mathrm{C}_{1} \mathrm{Im}\right] \mathrm{Cl}$ and $\left[\mathrm{C}_{2} \mathrm{C}_{1} \mathrm{Im}\right] \mathrm{Cl}$ are both in solid form at room temperature with melting point between $70-90{ }^{\circ} \mathrm{C}$. The two ILs were stored at room temperature in dry and well ventilated area. $6 \mathrm{~N}$ hydrochloric acid solution was purchased from Sigma-Aldrich, St. Louis, MO, USA.

\section{Screening of feedstock blends at milliliter scale}

As shown in Table 1, sixteen MSW blends were developed with different blending ratios. They were initially pretreated at $160{ }^{\circ} \mathrm{C}$ for 2 hours using $\left[\mathrm{C}_{2} \mathrm{C}_{1} \mathrm{Im}\right] \mathrm{Cl}$ in $50 \mathrm{~mL}$ pressure tubes (Ace Glass Inc., Vineland, NJ, USA). Typically, $0.5 \mathrm{~g}$ blends were pre-mixed with $4.5 \mathrm{~g}\left[\mathrm{C}_{2} \mathrm{C}_{1} \mathrm{Im}\right] \mathrm{Cl}$ and then loaded to the tube reactors. The reactors were then heated in an oil bath at $160{ }^{\circ} \mathrm{C}$ for 2 hours. After pretreatment, tube reactors were cooled down to $105{ }^{\circ} \mathrm{C}$ for acidolysis process following the previous report. ${ }^{3,4,32}$ Briefly, weighed amount of $4 \mathrm{~N} \mathrm{HCl}$ was added to the IL/blends slurry $(t=0 \mathrm{~min}$, acid loading: $10 \% \mathrm{w} / \mathrm{w}$ to feedstock blends), and certain amount of deionized water was added at different time intervals ( $t=10 \mathrm{~min}, 15-60 \mathrm{~min}$ ) to result in targeted water concentrations of $5 \%, 20 \%$ and $43 \%$. The acidolysis process continued for a total of 2.5 hours.

\section{IL process scale-up}

IL pretreatments were carried out in a $10 \mathrm{~L}$ Parr vessel (Parr Instrument Company, model: 4555-58, Moline, IL, USA). This Hastelloy C276 reactor is acid tolerant and has been upgraded in two ways to meet process needs: (1) the magnetically coupled drive of anchor impeller was replaced by a self-sealing packed gland drive to handle high solid loading and viscosity; (2) the 
Table 116 MSW blends with different feedstock blending ratios (wt\%) and their chemical compositions (wt\%)

\begin{tabular}{|c|c|c|c|c|c|c|c|c|c|c|c|c|}
\hline \multirow{2}{*}{$\begin{array}{l}\text { Blend } \\
\text { no. }\end{array}$} & \multicolumn{5}{|c|}{ Blending ratios } & \multicolumn{7}{|c|}{ Chemical compositions of MSW blends } \\
\hline & Abbr. & $\mathrm{CS}^{a}$ & $\mathrm{SG}^{a}$ & $\mathrm{GC}^{a}$ & $\mathrm{NRP}^{a}$ & Glucan (\%) & Xylan (\%) & Galactan (\%) & Arabinan (\%) & Acetate (\%) & Lignin (\%) & Ash (\%) \\
\hline 2 & CG8 $: 2$ & 80 & - & 20 & - & $31.5 \pm 1.1$ & $18.6 \pm 0.8$ & $1.7 \pm 0.0$ & $3.2 \pm 0.0$ & $1.4 \pm 0.1$ & $15.1 \pm 0.1$ & $7.4 \pm 0.1$ \\
\hline 3 & CG7 : 3 & 70 & - & 30 & - & $29.9 \pm 0.3$ & $18.3 \pm 0.2$ & $1.9 \pm 0.0$ & $3.5 \pm 0.0$ & $1.2 \pm 0.1$ & $16.1 \pm 0.0$ & $8.0 \pm 0.0$ \\
\hline 4 & CG6 : 4 & 60 & - & 40 & - & $26.8 \pm 0.2$ & $16.2 \pm 0.1$ & $1.8 \pm 0.0$ & $3.5 \pm 0.0$ & $1.1 \pm 0.0$ & $12.7 \pm 2.6$ & $8.6 \pm 0.9$ \\
\hline 7 & SG7 : 3 & - & 70 & 30 & - & $29.9 \pm 0.1$ & $17.9 \pm 0.4$ & $1.6 \pm 0.0$ & $3.3 \pm 0.0$ & $2.0 \pm 0.0$ & $15.8 \pm 0.3$ & $7.5 \pm 0.2$ \\
\hline 8 & SG6 $: 4$ & - & 60 & 40 & - & $28.7 \pm 0.1$ & $16.7 \pm 0.1$ & $1.6 \pm 0.0$ & $3.3 \pm 0.0$ & $1.7 \pm 0.0$ & $14.5 \pm 0.0$ & $7.9 \pm 0.4$ \\
\hline 9 & CS9 : 1 & 90 & 10 & - & - & $36.0 \pm 0.2$ & $24.1 \pm 0.1$ & $1.7 \pm 0.0$ & $3.4 \pm 0.0$ & $0.7 \pm 0.0$ & $16.4 \pm 0.3$ & $4.6 \pm 0.5$ \\
\hline 10 & CS8 $: 2$ & 80 & 20 & - & - & $34.2 \pm 0.1$ & $23.8 \pm 0.1$ & $1.5 \pm 0.0$ & $3.2 \pm 0.0$ & $1.9 \pm 0.0$ & $16.8 \pm 0.3$ & $5.0 \pm 0.2$ \\
\hline 11 & CN9 : 1 & 90 & - & - & 10 & $40.0 \pm 0.7$ & $22.5 \pm 0.6$ & $1.2 \pm 0.4$ & $3.3 \pm 0.1$ & $0.8 \pm 0.3$ & $16.0 \pm 0.0$ & $4.7 \pm 0.1$ \\
\hline 12 & CN8 $: 2$ & 80 & - & - & 20 & $40.7 \pm 0.3$ & $20.7 \pm 0.3$ & $1.5 \pm 0.1$ & $3.2 \pm 0.0$ & $1.5 \pm 0.0$ & $16.2 \pm 0.1$ & $6.7 \pm 0.1$ \\
\hline
\end{tabular}

${ }^{a}$ CS: corn stover, SG: switchgrass, GC: grass clippings, NRP: non-recyclable paper.

original sampling port was replaced by a 3-way valve allowing acid/water injection during the process. ${ }^{3}$ To ensure uniform heating and efficient mass transfer, the IL was firstly loaded into the reactor and melted through preheating to $80{ }^{\circ} \mathrm{C}$. Then $10 \%$ $(\mathrm{w} / \mathrm{w}, 340 \mathrm{~g})$ or $15 \%(\mathrm{w} / \mathrm{w}, 510 \mathrm{~g})$ solids were loaded and mixed with the melted IL at a low agitation speed $(50 \mathrm{rpm})$. IL pretreatment was performed at three different temperatures $\left(120{ }^{\circ} \mathrm{C}, 140{ }^{\circ} \mathrm{C}\right.$ or $160{ }^{\circ} \mathrm{C}$ ) with a fixed time ( 2 hours).

After IL pretreatment, the reaction temperature was lowered to $105{ }^{\circ} \mathrm{C}$ for acidolysis. After 15 minutes equilibration, acidolysis started ( $t=0 \mathrm{~min})$ with addition of $4 \mathrm{~N}$ hydrochloric acid (10\% of the feedstock blend) into the reactor through the injection port. The solution became acidic and water content was raised to $5 \%$ of the total weight. At $t=10 \mathrm{~min}$, more water (643 $\mathrm{g}$ or $539 \mathrm{~g}$ ) was injected and the water content reached $20 \%$ (w/w). During $t=15-60 \mathrm{~min}$, more water (according to Table 2) was pumped into the reactor at a constant rate. The mixture was incubated at $105{ }^{\circ} \mathrm{C}$ for another $90 \mathrm{~min}$. Samples were taken every $30 \mathrm{~min}$ to monitor the sugar profile. Process details are summarized in Table 2.

\section{Product recovery}

After acidolysis, the product slurry was cooled to room temperature and then pumped into a basket centrifuge (Western States Machine Company, Model STM-2000 Pilot scale filtering centrifuge, Fairfield, $\mathrm{OH}$, USA) for solid-liquid separation. A polypropylene filter bag $\left(\mathrm{PN}-038086,14^{\prime \prime} \times 6^{\prime \prime} \times 2^{\prime \prime}, 30\right.$ micron) was used to capture the recovered solids. After collection, the solids were further washed with $30 \mathrm{~L}$ water $\left(50{ }^{\circ} \mathrm{C}\right)$ to ensure removal of the residual IL and separation of sugar hydrolysate. Recovered solids were then dried in an oven at $42{ }^{\circ} \mathrm{C}$ for 48 hours and subjected to compositional analysis. Liquid samples were collected for sugar analysis.

\section{Analytical methods}

The compositional analysis of MSW blends before and after pretreatment was carried out following the NREL standard twostep sulfuric acid hydrolysis procedure. ${ }^{38}$ The structural carbohydrates, lignin and ash contents were quantified.

Table 2 Parameters of IL pretreatment and acidolysis processes at $6 \mathrm{~L}$ scale

Acidolysis process (at $\left.105^{\circ} \mathrm{C}\right)$

IL pretreatment process, $120 \mathrm{~min}$

\begin{tabular}{|c|c|c|c|c|}
\hline \multicolumn{2}{|l|}{$0-10 \mathrm{~min}$} & $10-15 \min$ & $15-60 \mathrm{~min}$ & $60-150 \mathrm{~min}$ \\
\hline $\begin{array}{l}4 \mathrm{~N} \mathrm{HCl} \\
\text { (g) }\end{array}$ & $\begin{array}{l}\text { 1st water } \\
\text { addition }^{a}(\mathrm{~g})\end{array}$ & $\begin{array}{l}\text { 2nd water } \\
\text { addition }^{a}(\mathrm{~g})\end{array}$ & $\begin{array}{l}\text { 3rd water } \\
\text { addition }^{a}(\mathrm{~g})\end{array}$ & Incubate \\
\hline 250 & 0 & 643 & 1732 & Incubate \\
\hline
\end{tabular}

$\left[\mathrm{C}_{4} \mathrm{C}_{1} \mathrm{Im}\right] \mathrm{Cl}$

$160{ }^{\circ} \mathrm{C} ;\left[\mathrm{C}_{4} \mathrm{C}_{1} \mathrm{Im}\right] \mathrm{Cl}$

$15 \% \quad 3400 \quad 510$

$2890 \quad 375$

0

539

${ }^{a}$ The water contents (w/w) in the system after each addition are $5 \%, 20 \%$ and $43 \%$. 
Absorbance reading of acid soluble lignin was taken at $205 \mathrm{~nm}$ using a spectrophotometer (Thermo Fisher Scientific, GENESYS 10S UV/Vis, Waltham, MA, USA). Quantification of monosaccharides was conducted using a High Performance Liquid Chromatography (Thermo Fisher Scientific, Ultimate 3000, Waltham, MA, USA), which is equipped with an Aminex HPX-87H column (Bio-Rad, $300 \times 7.8 \mathrm{~mm}$, Hercules, CA, USA) and a Refractive Index (RI) detector. Mobile phase is $5 \mathrm{mM}$ sulfuric acid with a flow rate at $0.6 \mathrm{~mL} \mathrm{~min}^{-1}$ and column oven temperature at $65{ }^{\circ} \mathrm{C}$. RI detector is heated at $50{ }^{\circ} \mathrm{C}$. The samples were filtered using $0.45 \mu \mathrm{m}$ centrifuge filter and then diluted with $5 \mathrm{mM}$ sulfuric acid for injection.

The IL and solid streams before and after the process were subjected to energy density measurement using the calorimeter (IKA® Works, Inc., C2000 Basic, Wilmington, NC, USA) with a previously established method..$^{39,40}$ The calorimeter was calibrated using standard benzoic acid (Sigma-Aldrich, St. Louis, MO, USA). The energy content was determined by burning a known amount of samples with excess of oxygen in a sealed chamber according to the method reported previously. ${ }^{40}$

\section{Results and discussion}

\section{MSW blends screening at milliliter scale}

Sixteen MSW blends were initially screened at $10 \mathrm{~mL}$ scale by evaluating sugar yields and identification of the most promising blends for scale-up. Standard deviations of the sugar yields using the $50 \mathrm{~mL}$ pressure tube reactors are within 10\% (Fig. 1). The sixteen blends cover a range of NRP and GC concentrations from $10-40 \%$ of the mixture combined with either a traditional herbaceous feedstock, corn stover (CS), or a model energy crop, switchgrass (SG). As the amount of waste material in the blend increases, the overall feedstock costs will decrease; however, NRP and GC are also "dirtier" feedstocks and likely contain impurities that could impact conversion efficiencies. Therefore, the best blend will be a compromise between conversion efficiency and feedstock cost. The results show that all the blends can be effectively converted to sugars through the IL-acidolysis pathway, with sugar yields varying at different feedstock blend

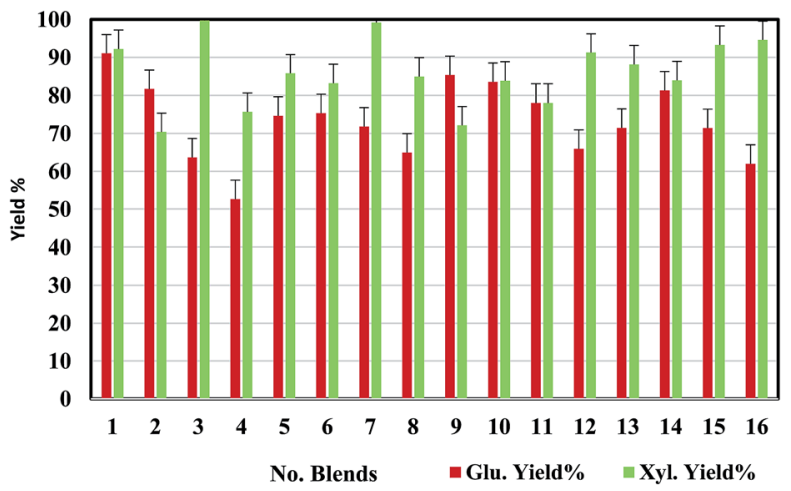

Fig. 1 Glucose and xylose yields from acidolysis of sixteen MSW blends after pretreatment with selected conditions $\left(\left[\mathrm{C}_{2} \mathrm{C}_{1} \mid \mathrm{m}\right] \mathrm{Cl}\right.$, $160{ }^{\circ} \mathrm{C}, 2 \mathrm{~h}$ ) at $10 \mathrm{~mL}$ scale (see Table 1 for sample IDs and compositions). ratios. Since the feedstock recalcitrance or composition varies, the selected pretreatment condition $\left(\left[\mathrm{C}_{2} \mathrm{C}_{1} \mathrm{Im}\right] \mathrm{Cl}, 160{ }^{\circ} \mathrm{C}, 2 \mathrm{~h}\right)$ may not be optimal for all sixteen blends. As shown in Fig. 1, the blends with 90\% corn stover (CG9:1 and CS9:1) achieved higher glucose release ( $91 \%$ and $85 \%$ yield), and those with $30 \%$ grass clipping (CG7 : 3 and SG7 :3) were superior in terms of xylose release (99\% yield). With more NRP or GC blending into the feedstock, glucose yields drop significantly (blends 1-4 and blends 14-16). This indicates that the selected MSW streams are more recalcitrant than the model feedstocks (corn stover or switchgrass) either due to the higher ash content or other contaminants present in the streams.

From a cost perspective, geographic location plays a large role in deciding the feedstock cost. For the cost analysis in this study, we assumed the location used in the INL 2017 feedstock design case, as Kansas. ${ }^{37}$ We also utilized all of the assumptions in the design case for feedstock logistics operations and costs. All of the blends assessed in this study met the $\$ 80$ per ton (2011 $\$$ ) with these assumptions if feedstock quality parameters were ignored. The 2017 design case suggested two quality parameters: a total ash content of less than 5\% and carbohydrate content (glucan + xylan) of greater than $59 \%$. The ash content is related to disposal costs incurred to get rid of ash in excess of the $5 \%$ and a dockage of $\$ 2.25$ per ton per percent ash over $5 \%$ was assumed. The carbohydrate specification is required for biorefineries to obtain the required biofuel yields for the NREL design case $\mathrm{e}^{\mathbf{4 1 , 4 2}}$ and the dockage was set at a flat cost of $\$ 6.10$ per ton.

Most of the blends were over the 5\% ash specification and would have an associated dockage applied. Among the four initial feedstocks (NRP: $49.2 \%$ glucan, $10.6 \%$ xylan, $11.4 \%$ lignin, and $22.3 \%$ ash; CS: $36.4 \%$ glucan, $23.7 \%$ xylan, $16.8 \%$ lignin, and $4.3 \%$ ash; SG: $35.0 \%$ glucan, $23.7 \%$ xylan, $17.3 \%$ lignin, and $3.8 \%$ ash; GC: $18.2 \%$ glucan, $7.4 \%$ xylan, $12.0 \%$ lignin, and $15.9 \%$ ash), NRP has the highest glucan content followed by CS and SG. They all have similar lignin content ranging from $11.4 \%$ to $17.3 \%$. None of the blends containing GC met the carbohydrate specification (Table 1) due to their low glucan/xylan content. Also none of the SG/NRP blends met the carbohydrate specification. Since none of the blends would meet the $\$ 80$ per ton target if the carbohydrate dockage was applied, we ruled out all blends that did not meet that quality parameter leaving only CS/SG (90/10), and CS/NRP blends (90/ 10, 80/20 and 70/30). Applying the ash dockage to these blends resulted in costs of \$78.43, \$76.68, \$78.89 and \$76.14, respectively. Since all of these blends had similar costs and similar carbohydrate contents as well as similar sugar yields, we picked feedstock blend \#12 (CN8 : 2) for scale-up studies. The lab scale screening results showed that $65 \%$ glucose and $91 \%$ xylose yields were obtained with $\left[\mathrm{C}_{2} \mathrm{C}_{1} \mathrm{Im}\right] \mathrm{Cl}$ pretreatment of CN8 : 2 at $160{ }^{\circ} \mathrm{C}$ for 2 hours followed by acidolysis at $105{ }^{\circ} \mathrm{C}$.

\section{IL pretreatment and acidolysis process scale-up}

The one-pot IL acidolysis process flow is described in Fig. 2. Well-mixed MSW blend was subjected to IL pretreatment first under different conditions. Acidolysis was initiated by pumping 


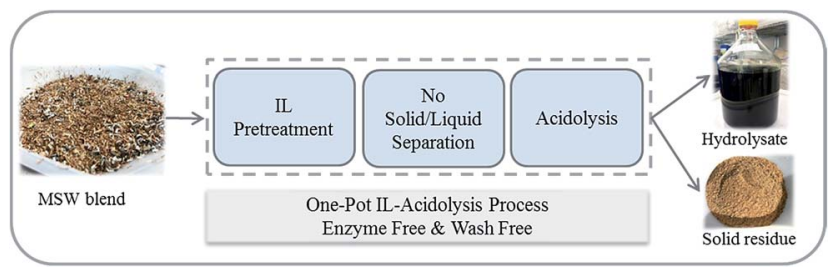

Fig. 2 Process flow of the conversion process using chloride-based IL.

in acid $(\mathrm{HCl})$ and water to the slurry directly without the intermediate solid/liquid separation or washing steps. The liquid hydrolysate and solid residues were separated by centrifugation after acidolysis. Elimination of the water washing steps significantly reduced volume of water used compared to more traditional IL-based process. Moreover, the sugars are released in situ without the need of enzymes which will potentially reduce the process cost.

During the scale-up experiment under the same conditions $\left(\left[\mathrm{C}_{2} \mathrm{C}_{1} \mathrm{Im}\right] \mathrm{Cl}, 160{ }^{\circ} \mathrm{C}, 2 \mathrm{~h}\right)$, lower glucose yield ( $58 \%$ vs. $\left.65 \%\right)$ and xylose yield ( $35 \%$ vs. $91 \%)$ were obtained compared to small scale results. The decreased yield is likely due to the conditions examined for small scale screening not necessarily being optimal for the blend and/or being replicable for scale-up to $6 \mathrm{~L}$. This could result in a change of apparent reaction severity as a function of the different reactor configurations $(50 \mathrm{~mL}$ tube reactor $v s .10 \mathrm{~L}$ Parr). In this case, the IL pretreatment in the $10 \mathrm{~L}$ Parr reactor took 90 minutes to reach $160{ }^{\circ} \mathrm{C}$ given maximum power supply, while the small scale tube reactors only took 15-20 min to reach the target temperature. This resulted in the biomass being subjected to IL treatment for a longer period of time. Therefore, a series of studies were conducted to further optimize this process aiming to achieve higher sugar yields. The main factors affecting the sugar yields such as IL type, pretreatment temperature, solid loading, and degree of sugar degradation were evaluated. The results of optimization are summarized in Table 3 and plotted in Fig. 3 and 4 .

Generally, higher severity with increased pretreatment temperature results in higher glucose yield, and xylose yield decreases at the same time due to xylose degradation. For the $\left[\mathrm{C}_{2} \mathrm{C}_{1} \mathrm{Im}\right] \mathrm{Cl}$ pretreatment, the highest glucose yield of $58 \%$ was achieved at $160{ }^{\circ} \mathrm{C}$, while the highest xylose yield of $47 \%$ was obtained at the lower temperature of $120^{\circ} \mathrm{C}$. There was $6-11 \%$ glucose degraded to hydroxymethylfurfural (HMF), and 10-18\% xylose to furfural (FF). The $\left[\mathrm{C}_{4} \mathrm{C}_{1} \mathrm{Im}\right] \mathrm{Cl}$ also showed a maximum glucose yield at $160{ }^{\circ} \mathrm{C}$ of $70.9 \%$ while the maximum xylose yield of $55.7 \%$ was observed at $140{ }^{\circ} \mathrm{C}$ although the xylose yield at $160{ }^{\circ} \mathrm{C}$ was only slightly lower at $55.6 \%$. For both ILs the range of glucose degradation to HMF was $3-10 \%$ and xylose degradation to $\mathrm{FF}$ was $10-18 \%$. In our previous study using more pristine materials such as newspaper and office paper, a similar level of glucose $(8 \%)$ and xylose (18\%) degradation was shown $\left(\left[\mathrm{C}_{2} \mathrm{C}_{1} \mathrm{Im}\right] \mathrm{Cl}, 140{ }^{\circ} \mathrm{C}, 2 \mathrm{~h}, 6 \mathrm{~L}\right) .{ }^{3}$ Under the current optimized condition (Table 3), the glucose yield of the actual NRP blends examined in this work was higher $\left(58 \%\right.$ vs. $51 \%$ in $\left[\mathrm{C}_{2} \mathrm{C}_{1} \mathrm{Im}\right] \mathrm{Cl}$; $71 \%$ vs. $58 \%$ in $\left[\mathrm{C}_{4} \mathrm{C}_{1} \mathrm{Im}\right] \mathrm{Cl}$ ) compared to the previous study, ${ }^{3}$ and xylose yield was lower ( $47 \%$ vs. $70 \%$ in $\left[\mathrm{C}_{2} \mathrm{C}_{1} \mathrm{Im}\right] \mathrm{Cl} ; 56 \%$ vs. $87 \%$ in $\left.\left[\mathrm{C}_{4} \mathrm{C}_{1} \operatorname{Im}\right] \mathrm{Cl}\right)$.

Overall, $\left[\mathrm{C}_{4} \mathrm{C}_{1} \mathrm{Im}\right] \mathrm{Cl}$ had better pretreatment performance than $\left[\mathrm{C}_{2} \mathrm{C}_{1} \mathrm{Im}\right] \mathrm{Cl}$ in terms of sugar yields (condition 4-6, Fig. 4). The maximum $71 \%$ glucose yield and $56 \%$ xylose yield were achieved in condition 6 with pretreatment temperature at $160{ }^{\circ} \mathrm{C}$ for 2 hours. The glucose yield obtained under the optimized conditions (\#6) surpassed the small scale ( $71 \%$ vs. $65 \%)$. Since the glucan content $(40.7 \%)$ is twice as much as xylan $(20.7 \%)$ in the CS/NRP blend and most of the fermentation organisms prefer to utilize glucose over xylose, higher glucose yields were more desired during the optimization. An increase in solid loadings from $10 \%$ to $15 \%$ was also examined since a more concentrated hydrolysate is desirable (\#7: $27 \mathrm{~g} \mathrm{~L} \mathrm{~L}^{-1}$ glucose and $10 \mathrm{~g} \mathrm{~L}^{-1}$ xylose $v s$. \#6: $20 \mathrm{~g} \mathrm{~L}^{-1}$ glucose and $9 \mathrm{~g} \mathrm{~L}^{-1}$ xylose); however, both glucose and xylose yields decreased by $7 \%$ and $14 \%$.

IL/CS/NRP slurries were still viscous after the pretreatment, indicative of the large molecular weight of the dissolved biopolymers. ${ }^{43}$ Oligomers were gradually converted to monomers during the acidolysis incubation. Fewer solid residues were recovered due to the higher pretreatment temperature. Sugar yields during the acidolysis incubation were plotted in Fig. 3 and 4. According to the sampling results at a 30 minute interval, glucose and xylose yields generally levelled off after $1 \mathrm{~h}$ of acidolysis incubation with comparison to $48-72 \mathrm{~h}$ for enzymatic saccharification.

Table 3 Summary of the conditions, sugar yields, solid recoveries and sugar degradations for scale-up study at $6 \mathrm{~L}$

\begin{tabular}{|c|c|c|c|c|c|c|c|c|}
\hline 1 & {$\left[\mathrm{C}_{2} \mathrm{C}_{1} \mathrm{Im}\right] \mathrm{Cl}$} & 10 & $120 / 2$ & 44.5 & 46.9 & 21.3 & 6.0 & 17.0 \\
\hline 3 & {$\left[\mathrm{C}_{2} \mathrm{C}_{1} \mathrm{Im}\right] \mathrm{Cl}$} & 10 & $160 / 2$ & 57.8 & 34.6 & 6.8 & 11.3 & 10.2 \\
\hline 4 & {$\left[\mathrm{C}_{4} \mathrm{C}_{1} \mathrm{Im}\right] \mathrm{Cl}$} & 10 & $120 / 2$ & 53.7 & 51.0 & 13.6 & 7.0 & 18.0 \\
\hline 5 & {$\left[\mathrm{C}_{4} \mathrm{C}_{1} \mathrm{Im}\right] \mathrm{Cl}$} & 10 & $140 / 2$ & 62.0 & 55.7 & 16.9 & 3.1 & 12.0 \\
\hline
\end{tabular}

${ }^{a}$ HMF: hydroxymethylfurfural; FF: furfural. 

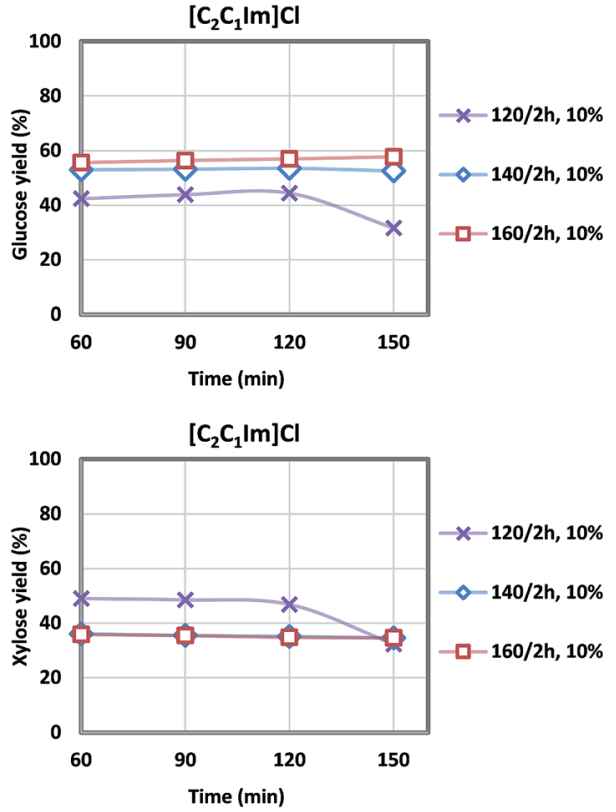

Fig. 3 Glucose and xylose yields during acidolysis incubation after $\left[\mathrm{C}_{2} \mathrm{C}_{1} \mathrm{Im}\right] \mathrm{Cl}$ pretreatment at various temperatures ( $6 \mathrm{~L}$ scale), note xylose yields at 140/2 $\mathrm{h}$ and 160/2 h overlap.
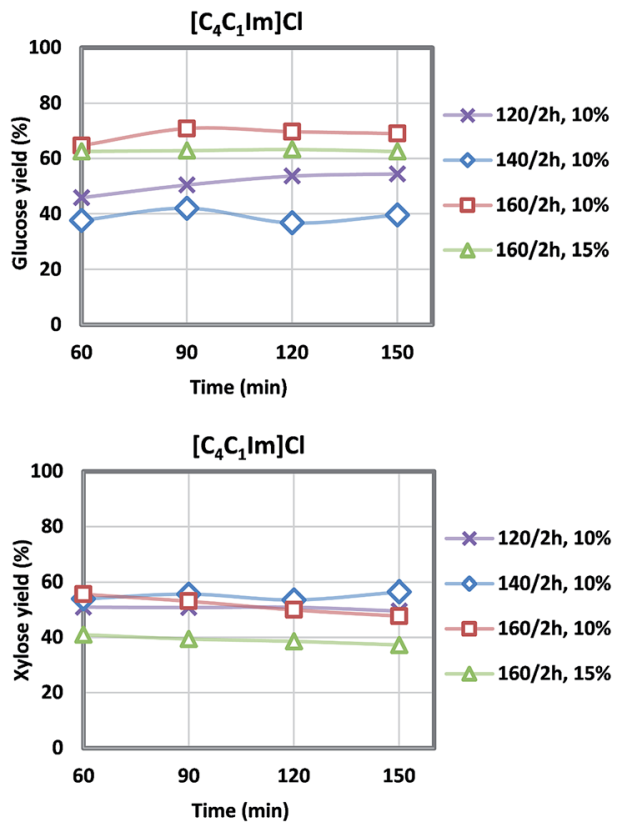

Fig. 4 Glucose and xylose yields during acidolysis incubation after $\left[\mathrm{C}_{4} \mathrm{C}_{1} \mathrm{Im}\right] \mathrm{Cl}$ pretreatment at various temperatures ( $6 \mathrm{~L}$ scale).

\section{Mass and energy flow}

In the untreated CS/NRP blend, glucan accounts for $40.7 \%$ of the mass with another $20.7 \%$ for xylan, $16.2 \%$ for lignin and $6.7 \%$ for ash. After IL pretreatment and acidolysis, most glucan and xylan had been dissolved and then converted to either sugar monomers or degradation products which remained in the hydrolysate stream. Unreacted solids were collected, washed to
Table 4 Composition of CS/NRP blends and recovered solid residues (6 L scale)

\begin{tabular}{lcllr}
\hline Condition & Glucan (\%) & Xylan (\%) & Lignin (\%) & Ash (\%) \\
\hline Untreated & $40.7 \pm 0.3$ & $20.7 \pm 0.3$ & $16.2 \pm 0.1$ & $6.7 \pm 0.1$ \\
1 & $38.3 \pm 2.0$ & na. & $46.2 \pm 1.5$ & $8.8 \pm 0.5$ \\
2 & $14.9 \pm 2.8$ & na. & $66.4 \pm 3.7$ & $11.4 \pm 0.1$ \\
3 & $34.7 \pm 7.8$ & $17.6 \pm 5.6$ & $23.9 \pm 6.4$ & $2.0 \pm 0.1$ \\
4 & $59.0 \pm 5.4$ & $0.9 \pm 0.0$ & $20.3 \pm 4.6$ & $13.8 \pm 0.3$ \\
5 & $44.2 \pm 6.8$ & $2.3 \pm 0.4$ & $42.3 \pm 6.1$ & $8.7 \pm 2.9$ \\
6 & $4.8 \pm 1.8$ & $0.7 \pm 0.0$ & $49.5 \pm 1.6$ & $42.4 \pm 0.5$ \\
7 & $4.5 \pm 0.4$ & na. & $76.7 \pm 0.2$ & $0.8 \pm 0.4$
\end{tabular}

neutral $\mathrm{pH}$ and dried for compositional analysis. As shown in Table 4, recovered solids were rich in lignin and ash. Compared to the untreated blend, the lignin content in solid residues recovered from condition \#2 increased from $16.2 \%$ to $66.4 \%$ and ash content increased from $6.7 \%$ to $11.4 \%$. The low carbohydrate content after IL-acidolysis is also an indicator of the efficient sugar conversion to the liquid stream. In condition $\# 6$, only $c a$. $5 \%$ of the carbohydrate remained in the solid residues with $49.5 \%$ as lignin, and $42.4 \%$ as ash.

The mass and energy flow of the IL pretreatment, acidolysis, and subsequent solid/liquid separation for condition \#6 were summarized in Fig. 5 to develop a clear overview of the technology scale-up. On the $340 \mathrm{~g}$ basis of untreated CS/NRP (80/20) blend, only $1.3 \mathrm{~g}$ of dry solid residues was recovered after solid/ liquid separation containing $4.8 \%$ glucan, $0.7 \%$ xylan, $49.5 \%$ lignin and $42.4 \%$ ash. In the hydrolysate, $70.9 \%$ glucan of the untreated blend was released to glucose and 55.6\% xylan was converted to xylose. Also, 7.3\% glucan degraded to HMF and $13.3 \%$ xylan degraded to FF. About $3.8 \%$ glucan and $2.5 \%$ xylan were left in the wash. Overall, the glucan balance closure on the basis of the recovered solids, the wash and hydrolysate streams $(82 \%)$ is higher than xylan $(71 \%)$, which is attributed to the stronger resistance of glucose to degradation during the process. $^{19}$

During the conversion process, a significant amount of lignin (99\%) was also solubilized in the hydrolysate stream causing the lignin reduction in the solid stream. Further lignin separation is necessary for sugar upgrading and/or IL recycling. ${ }^{3,4,39}$ Compared to the untreated blend, the solid residues are rich in lignin content ( $49.5 \%$ vs. $16.2 \%)$ due to the efficient sugar extraction during the IL-acidolysis process. This result is similar to previous reports by using the IL: 1-ethyl-3methylimidazolium acetate $\left(\left[\mathrm{C}_{2} \mathrm{C}_{1} \mathrm{Im}\right] \mathrm{OAc}\right)$ as pretreatment solvent followed by enzymatic saccharification ${ }^{3,39}$ with largely reduced processing time ( $4 \mathrm{~h} v$ s. over $2-3$ days) and elimination of costly enzymes.

Energy density is important in the overall energy and cost balance of the biofuel production process. A strong positive correlation was found between energy density and lignin content in biomass samples. ${ }^{40}$ Similar trends were observed in this study. Compared with untreated blend, the lignin content was significantly increased due to the efficient conversion of polysaccharides. Correspondingly, energy density of untreated blend $\left(17 \mathrm{~kJ} \mathrm{~g}^{-1}\right)$ and solid residues after the process $\left(31 \mathrm{~kJ} \mathrm{~g}^{-1}\right)$ 


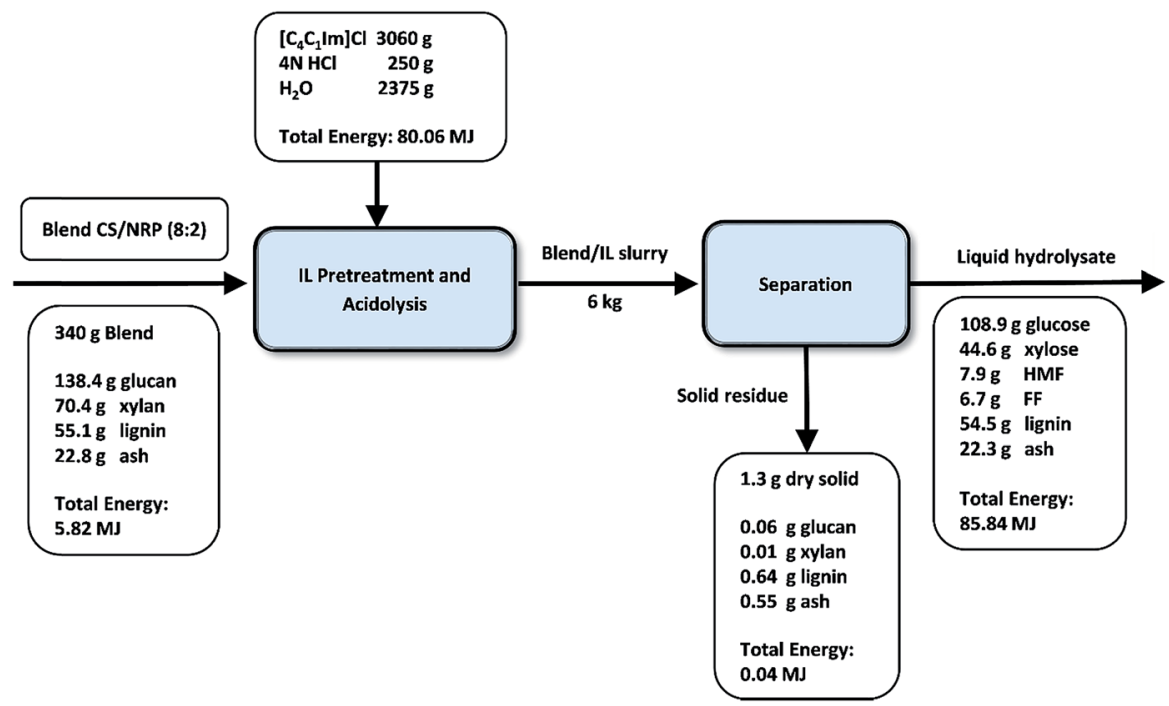

Fig. 5 Mass and energy flow of blend \#12 CS/NRP (80/20) with pretreatment in $\left[\mathrm{C}_{4} \mathrm{C}_{1} \mathrm{Im}\right] \mathrm{Cl}$ at $160{ }^{\circ} \mathrm{C}$ for $2 \mathrm{~h}$ and $10 \%$ (w/w) solid loading (6 L scale).

tracks well with their respective lignin content. As summarized in Fig. 5, full energy recovery is obtained with high energy content left in the liquid stream.

\section{Conclusions}

Model feedstocks (corn stover and switchgrass) blending with selected MSW streams shows great promise for generation of sugars as intermediates for production of fuels or chemicals. Corn stover and non-recyclable paper blend (CN8:2) is the most promising blend with the low cost (\$78.89 per ton), high glucan + xylan content $(61.4 \%)$ and abundant NRP streams from household waste. Chloride-based IL $\left(\left[\mathrm{C}_{2} \mathrm{C}_{1} \mathrm{Im}\right] \mathrm{Cl}\right.$ or $\left.\left[\mathrm{C}_{4} \mathrm{C}_{1} \mathrm{Im}\right] \mathrm{Cl}\right)$ pretreatment followed by acidolysis is efficient for extracting sugars from various MSW blends. The IL-acidolysis process has been successfully scaled up by 600 fold ( $6 \mathrm{~L}$ vs. $10 \mathrm{~mL}$ ) using CN8 : 2 blend, with a maximum $71 \%$ glucose yield and 56\% xylose yield under current optimized conditions $\left(\left[\mathrm{C}_{4} \mathrm{C}_{1} \mathrm{Im}\right] \mathrm{Cl}\right.$, $\left.160{ }^{\circ} \mathrm{C}, 2 \mathrm{~h}\right)$. The results indicate the feasibility of incorporating MSW, especially NRP, as a robust blending agent to provide lower cost biorefinery feedstock inputs. These scale-up results emphasize the importance of the process evaluation at the intermediate sale (lab to bench scale) before moving forward to pilot scale.

\section{Acknowledgements}

This work was supported by funding from the Department of Energy (DOE) the Office of Energy Efficiency and Renewable Energy's Bioenergy Technology Office (BETO). The funding was provided as an annual operating plan to each of the three national laboratories: Lawrence Berkeley, Sandia, and Idaho National Laboratories. Advanced Biofuels Process Demonstration Unit would like to acknowledge core funding support from BETO, and funding from the American Recovery and Reinvestment Act. FX, SS and BAS would like to acknowledge the supported by the DOE Office of Science, Office of Biological and Environmental Research under Contract No. DE-AC0205CH11231. CL and VST would like to acknowledge the support from DOE Idaho Operations Office under Contract DEAC07-05ID14517.

\section{References}

1 United States Environmental Protection Agency, Advancing Sustainable Materials Management: 2013 Fact Sheet, United States Environmental Protection Agency, June 2015.

2 A. P. C. Faaij, Bio-energy in Europe: changing technology choices, Energy Policy, 2006, 34(3), 322-342.

3 N. Sun, F. Xu, N. Sathitsuksanoh, V. S. Thompson, K. Cafferty, C. Li, et al., Blending municipal solid waste with corn stover for sugar production using ionic liquid process, Bioresour. Technol., 2015, 186, 200-206.

4 C. Li, L. Liang, N. Sun, V. S. Thompson, F. Xu, A. Narani, et al., Scale-up and process integration of sugar production by acidolysis of municipal solid waste/corn stover blends in ionic liquids, Biotechnol. Biofuels, 2017, 10(1), 13.

5 R. Perlack and B. U. S. Stokes, Billion-Ton Update: Biomass Supply for a Bioenergy and Bioproducts Industry, US Department of Energy, 2011, p. 227.

6 V. S. Thompson, J. A. Lacey, D. Hartley, M. A. Jindra, J. E. Aston and D. N. Thompson, Application of air classification and formulation to manage feedstock cost, quality and availability for bioenergy, Fuel, 2016, 180, 497505.

7 P. L. Eranki, B. D. Bals and B. E. Dale, Advanced regional biomass processing depots: a key to the logistical challenges of the cellulosic biofuel industry, Biofuels, Bioprod. Biorefin., 2011, 5(6), 621-630.

8 D. Klein-Marcuschamer, P. Oleskowicz-Popiel, B. A. Simmons and H. W. Blanch, Technoeconomic 
analysis of biofuels: a wiki-based platform for lignocellulosic biorefineries, Biomass Bioenergy, 2010, 34(12), 1914-1921.

9 C. Li, J. E. Aston, J. A. Lacey, V. S. Thompson and D. N. Thompson, Impact of feedstock quality and variation on biochemical and thermochemical conversion, Renewable Sustainable Energy Rev., 2016, 65, 525-536.

10 U.S. Environmental Protection Agency, Renewable Fuel Standard Program-Regulatory Impact Analysis, U.S. Environmental Protection Agency, 2010.

11 Y. Kalogo, S. Habibi, H. L. MacLean and S. V. Joshi, Environmental Implications of Municipal Solid WasteDerived Ethanol, Environ. Sci. Technol., 2007, 41(1), 35-41.

12 A. Z. Shi, L. P. Koh and H. T. W. Tan, The biofuel potential of municipal solid waste, GCB Bioenergy, 2009, 1(5), 317-320.

13 R. F. H. Dekker and A. F. A. Wallis, Autohydrolysis-explosion as pretreatment for the enzymic saccharification of sunflower seed hulls/autohydrolysis-explosion as pretreatment for the enzymic saccharification of sunflower seed hulls Trichoderma reesei, bioconversion of sunflower seed hulls into chemicals, liquid fuels, Biotechnol. Lett., 1983, 5, 311.

14 J. C. García, M. A. M. Zamudio, A. Pérez, F. López and J. L. Colodette, Search for optimum conditions of Paulownia autohydrolysis process and influence in pulping process, Environ. Prog. Sustainable Energy, 2011, 30(1), 92-101.

15 A. Jun, U. W. Tschirner and Z. Tauer, Hemicellulose extraction from aspen chips prior to kraft pulping utilizing kraft white liquor, Biomass Bioenergy, 2012, 37, 229-236.

16 H. Lu, R. Hu, A. Ward, T. E. Amidon, B. Liang and S. Liu, Hotwater extraction and its effect on soda pulping of aspen woodchips, Biomass Bioenergy, 2012, 39, 5-13.

17 N. D. Hinman, D. J. Schell, C. J. Riley, P. W. Bergeron and P. J. Walter, Preliminary estimate of the cost of ethanolproduction for SSF technology, Appl. Biochem. Biotechnol., 1992, 34-5, 639-649.

18 H. E. Grethlein and A. O. Converse, Common aspects of acid prehydrolysis and steam explosion for pretreating wood, Bioresour. Technol., 1991, 36(1), 77-82.

19 C. Li, B. Knierim, C. Manisseri, R. Arora, H. V. Scheller, M. Auer, et al., Comparison of dilute acid and ionic liquid pretreatment of switchgrass: biomass recalcitrance, delignification and enzymatic saccharification, Bioresour. Technol., 2010, 101(13), 4900-4906.

20 S. J. B. Duff and W. D. Murray, Bioconversion of forest products industry waste cellulosics to fuel ethanol: a review, Bioresour. Technol., 1996, 55(1), 1-33.

21 J. M. Wasikiewicz, F. Yoshii, N. Nagasawa, R. A. Wach and H. Mitomo, Degradation of chitosan and sodium alginate by gamma radiation, sonochemical and ultraviolet methods, Radiat. Phys. Chem., 2005, 73(5), 287-295.

22 Y. L. Zhao, Y. Wang, J. Y. Zhu, A. Ragauskas and Y. L. Deng, Enhanced enzymatic hydrolysis of spruce by alkaline pretreatment at low temperature, Biotechnol. Bioeng., 2008, 99(6), 1320-1328.

$23 \mathrm{~S}$. J. Liu, A kinetic model on autocatalytic reactions in woody biomass hydrolysis, J. Biobased Mater. Bioenergy, 2008, 2(2), 135-147.
24 J. K. Ko, J. S. Bak, M. W. Jung, H. J. Lee, I.-G. Choi, T. H. Kim, et al., Ethanol production from rice straw using optimized aqueous-ammonia soaking pretreatment and simultaneous saccharification and fermentation processes, Bioresour. Technol., 2009, 100(19), 4374-4380.

25 J. Y. Zhu and X. J. Pan, Woody biomass pretreatment for cellulosic ethanol production: technology and energy consumption evaluation, Bioresour. Technol., 2010, 101(13), 4992-5002.

26 S. P. S. Chundawat, B. S. Donohoe, L. Da Costa Sousa, T. Elder, U. P. Agarwal, F. Lu, et al., Multi-scale visualization and characterization of lignocellulosic plant cell wall deconstruction during thermochemical pretreatment, Energy Environ. Sci., 2011, 4(3), 973-984.

27 N. Sun, H. Rodríguez, M. Rahman and R. D. Rogers, Where are ionic liquid strategies most suited in the pursuit of chemicals and energy from lignocellulosic biomass, Chem. Commun., 2011, 47, 1405-1421.

28 C. Li, L. Sun, B. A. Simmons and S. Singh, Comparing the Recalcitrance of Eucalyptus, Pine, and Switchgrass Using Ionic Liquid and Dilute Acid Pretreatments, BioEnergy Res., 2012, 6(1), 14-23.

29 J. Shi, K. W. George, N. Sun, W. He, C. Li, V. Stavila, et al., Impact of Pretreatment Technologies on Saccharification and Isopentenol Fermentation of Mixed Lignocellulosic Feedstocks, BioEnergy Res., 2015, 8(3), 1004-1013.

30 J. A. Perez-Pimienta, M. G. Lopez-Ortega, J. A. ChavezCarvayar, P. Varanasi, V. Stavila, G. Cheng, et al., Characterization of agave bagasse as a function of ionic liquid pretreatment, Biomass Bioenergy, 2015, 75, 180-188.

31 T. L. Ruegg, E.-M. Kim, B. A. Simmons, J. D. Keasling, S. W. Singer, T. Soon Lee, et al., An auto-inducible mechanism for ionic liquid resistance in microbial biofuel production, Nat. Commun., 2014, 5, 3490.

32 N. Sun, H. Liu, N. Sathitsuksanoh, V. Stavila, M. Sawant, A. Bonito, et al., Production and extraction of sugars from switchgrass hydrolyzed in ionic liquids, Biotechnol. Biofuels, 2013, 6(1), 1-15.

33 N. Sun, W. Li, B. Stoner, X. Jiang, X. Lu and R. D. Rogers, Composite fibers spun directly from solutions of raw lignocellulosic biomass dissolved in ionic liquids, Green Chem., 2011, 13(5), 1158-1161.

34 F. Xu, Y.-C. Shi and D. Wang, Enhanced production of glucose and xylose with partial dissolution of corn stover in ionic liquid, 1-Ethyl-3-methylimidazolium acetate, Bioresour. Technol., 2012, 114, 720-724.

35 S. Singh, R. Arora, C. Li, I. P. Mathews and B. A. Simmons, Mixed Feedstocks Processing Using an Ionic Liquid, U.S. Pat., US20130183739 A1, 2013.

36 J. B. Binder and R. T. Raines, Fermentable sugars by chemical hydrolysis of biomass, Proc. Natl. Acad. Sci. U. S. A., 2010, 107(10), 4516-4521.

37 K. L. Kenney, K. G. Cafferty, J. Jacobson, I. J. Bonner, G. L. Gresham and J. R. Hess, et al., Feedstock Supply System Design and Economics for Conversion of Lignocellulosic Biomass to Hydrocarbon Fuels, Conversion 
Pathway: Biological Conversion of Sugars to Hydrocarbons: The 2017 Design Case, INL/EXT-13-30342, 2013.

38 Determination of structural carbohydrates and lignin in biomass, http://devafdc.nrel.gov/pdfs/9572.pdf, 2006.

39 C. Li, D. Tanjore, W. He, J. Wong, J. L. Gardner, K. L. Sale, et al., Scale-up and evaluation of high solid ionic liquid pretreatment and enzymatic hydrolysis of switchgrass, Biotechnol. Biofuels, 2013, 6(1), 154.

40 J. L. Gardner, W. He, C. Li, J. Wong, K. L. Sale, B. A. Simmons, et al., Calorimetric evaluation indicates that lignin conversion to advanced biofuels is vital to improving energy yields, $R S C A d v$. , 2015, 5(63), 51092-51101.

41 P. Lamers, E. C. D. Tan, E. M. Searcy, C. J. Scarlata, K. G. Cafferty and J. J. Jacobson, Strategic supply system design - a holistic evaluation of operational and production cost for a biorefinery supply chain, Biofuels, Bioprod. Biorefin., 2015, 9(6), 648-660.

42 R. Davis, L. Tao, C. Scarlata, E. C. D. Tan, J. Ross and J. Lukas, et al., NREL/TP-5100-62498 Process Design and Economics for the Conversion of Lignocellulosic Biomass to Hydrocarbons: Dilute-Acid and Enzymatic Deconstruction of Biomass to Sugars and Catalytic Conversion of Sugars to Hydrocarbons, National Renewable Energy Laboratory Technical Report, 2015.

43 W. Li, N. Sun and R. D. Rogers, Rapid dissolution of lignocellulosic biomass in ionic liquids using temperatures above the glass transition of lignin, Green Chem., 2011, 13(8), 2038-2047. 